\title{
Numerical simulation of volcanic plume dispersal from Usu volcano in Japan on 31 March 2000 using PUFF model
}

\author{
H. L. Tanaka ${ }^{1}$ and Kazumi Yamamoto ${ }^{2}$ \\ ${ }^{1}$ Institute of Geoscience, University of Tsukuba, Tsukuba 305-8571, Japan \\ ${ }^{2}$ Graduate School of Life and Environmental Sciences, University of Tsukuba, Tsukuba 305-8571, Japan
}

(Received February 14, 2002; Revised June 6, 2002; Accepted June 6, 2002)

\begin{abstract}
In this study, a volcanic ash tracking model called "PUFF" is applied to the actual eruption of Usu volcano on 31 March 2000 in order to infer the movement of airborne ash clouds for aviation safety. The PUFF model was developed and operated by the Alaska Volcano Observatory since the eruption of Redoubt volcano in 1989. The performance of the PUFF model is examined in this study based on the ground truth of the observed distribution of tephra on the ground. According to the model simulation, the ash plume erupted from Usu volcano first moved eastward for the New Chitose International Airport. As the upper air westerly wind gradually shifted to southerly wind, the ash front traveled from Chitose to Nemuro while the subsequent eruption plume directed toward the northeast over Sapporo area. The vertical cross sections and 3-D perspective image of the ash clouds are presented as a function of time. The model simulation was justified by the agreement between the modeled and observed distributions of tephra on the ground. The PUFF model with accurate wind information can simulate the location and the direction of the moving airborne ash cloud on a realtime basis, which may provide crucial information to aviation industry.
\end{abstract}

\section{Introduction}

Volcanic ash cloud floating and traveling in the air is a great concern to airline pilots. If a commercial jet aircraft encounters ash cloud, by chance, the damage could be serious enough to cause an engine failure. It is estimated that an accident of scratched wind shields and an engine failure would cost 1 million US dollars, whereas it would be 1 billion US dollars if the aircraft crashes into the ground. There was in fact an accident in December 1989. A KLM jumbo jet approaching Anchorage International Airport encountered airborne ash near Mt. McKinley erupted from Redoubt volcano. All of the four engines stopped by the dense ash clouds which melt and jammed in the engine (Hobbs et al., 1991; Casadevall, 1994). The jumbo jet lost the power and started the descent without control. Fortunately, one engine recovered as the engine cooled down when the aircraft was about 10000 feet above the ground, and the passengers could land safely at Anchorage International Airport. Similar troubles of commercial aircrafts were reported not only at the Alaskan route but also at the Oceanian route where a number of active volcanos line up (Onodera, 1997).

In order to avoid serious accidents of commercial aircrafts, realtime volcanic plume prediction models have been developed by some agencies. A three-dimensional (3-D) turbulent diffusion model was developed by Armienti and Macedonio (1988) using an observed upper air wind data and applied to Strombolian eruption of Mt. St. Helens in 1980. Glaze and Self (1991) constructed a turbulent diffusion model consid-

Copy right (c) The Society of Geomagnetism and Earth, Planetary and Space Science (SGEPSS); The Seismological Society of Japan; The Volcanological Society of Japan; The Geodetic Society of Japan; The Japanese Society for Planetary Sciences. ering the vertical wind shear and applied to Usu volcano in 1977 to see distributions of ash fall. They also estimated the distributions of ash fall of burugano type for Lascar volcano in Chile. Hurst and Turner (1999) developed a 3-D turbulent diffusion model called ASHFALL to predict volcanic ash fall for operational use. In this model, the regional distribution of the upper air wind is predicted by RAMS (Regional Atmospheric Modeling System). Turner and Hurst (2001) further combined HYPACT (Hybrid Particle and Concentration Transport Model) with RAMS to improve the model. The HYPACT/RAMS first computed the Lagrangian motion of ash particles from the point source at caldera. It then shifted to compute diffusion process in Eulerian distribution of the ash mixing ratio when the ash cloud spread wide enough, using $40 \mathrm{~km}$ grid mesh data from RAMS. Heffter and Stunder (1993) developed a transport dispersion model called VAFTAD (Volcanic Ash Forecast Transport and Dispersion) to predict ash plume floating in the air. They computed the mixing ratio of airborne ash using the predicted upper air wind on the grid mesh to predict the 3-D distribution and the movement of the ash cloud. A group of worldwide volcanic ash advisory services was organized to form volcanic ash advisory centers (VAACs) by nine organizations under the auspice of the International Civil Organization (ICAO). The Tokyo VAAC is one of the nine VAACs which was established in April 1997 at the Tokyo Aviation Weather Service Center. The Tokyo VAAC operates the Lagrangian and Eulerian models to forecast the position of the volcanic ash clouds (Tokyo Aviation Weather Service Center, 2001).

In parallel with those activities, Tanaka (1994), Searcy et 
al. (1998), and Yamamoto (2002) developed a realtime volcanic ash plume tracking model called PUFF for the purpose of realtime aviation safety in northeastern Pacific rim including Alaska volcanos. The model is operational under the Alaska Volcano Observatory at the Geophysical Institute of the University of Alaska Fairbanks since the eruption of Redoubt volcano in 1990 (Tanaka, 1991; Kienle et al., 1991; Dean et al., 1993). In their Lagrangian model, forecasted wind data are provided by UNIDATA and other model sources, and transport, diffusion, and gravitational fallout are considered in the model. The performance of the volcanic ash tracking model PUFF has been examined for Alaskan volcanos (Tanaka et al., 1993; Akasofu and Tanaka, 1993), but it must be further demonstrated by applications to actual eruptions occurring occasionally in the world.

In this study, our PUFF model was applied to the actual eruption of Usu volcano on 31 March 2000 in Hokkaido (Endoh et al., 2001). Compared with volcanos in the northern Pacific rim along Aleutian Island to Kamchatka, volcanos in Japan are surrounded by dense and advanced monitoring system for plume dispersal in the air 24 hours a day not only by the satellite images but also by the ground based and airborne TV monitoring facilities. Using the nearrealtime upper air wind data provided by Japan Meteorological Agency (JMA), we can conduct a sequence of actual predictions of volcanic plume movements. The model prediction provides us the location and the direction of the moving ash cloud in the air on a realtime basis, which gives crucial information to commercial and non-commercial aviation industry. It was a great opportunity for us to further tune many physical parameters of the PUFF model using information obtained associated with the Usu volcano monitoring system.

Section 2 describes the basic framework of the particle tracking PUFF model, with the physical processes of diffusion and gravitational fallout. The result of the model prediction is compared in Section 3 with ground observations of the ash fall. Based on the ash fall record on the ground, the 3-D dispersal and the movement of the airborne ash cloud is discussed in Section 4 of the summary and conclusions.

\section{Description of the Model}

The volcanic plume prediction model, so called PUFF, was constructed by Tanaka (1994) and reported in detail by Searcy et al. (1998) as an application of pollutant dispersion models (e.g., Praham and Christensen, 1977; Suck et al., 1978; Kai et al., 1988). The model is based on the 3-D Lagrangian form of the transport-diffusion equation. We assume a vertical column of pollutant source that diffuses along with the Gaussian distribution in the 3-D space. A diffusion approximation of the pollutant turbulent mixing is used with 3-D diffusion coefficients to evaluate the dispersion of the pollutant concentration. In the Lagrangian framework, a realization of the stochastic process of plume particles may be described by a random walk process (e.g., Chatfield, 1975). Here, the diffusion is simulated by a sufficiently large number of random variables $r_{i}(t), i=1 \sim M$, representing position vectors of $M$ particles from the origin of the volcanic crater. The diffusion is superimposed on convective transport and gravitational fallout.
With a discrete time increment $\Delta t$ ( $=5$ minutes), the Lagrangian form of the governing equation may be written as

$$
\left\{\begin{array}{c}
r_{i}(0)=S, \quad i=1 \sim M, \quad \text { for } t=0, \\
r_{i}(t+\Delta t)=r_{i}(t)+V \Delta t+D \Delta t+G \Delta t, \\
i=1 \sim M, \quad \text { for } t>0 .
\end{array}\right.
$$

where $r_{i}(t)$ is a position vector of an $i$-th particle at time $t$, $V=(u, v, w)$ is the local wind velocity to transport the particle, $D=\left(d_{h}, d_{h}, d_{v}\right)$ is a vector containing three Gaussian random numbers for diffusion, and $G$ is the gravitational fallout speed approximated by Stokes Law. Note that the Gaussian random numbers for diffusion have zero mean, and the standard deviations specified by $\left(c_{h}, c_{h}, c_{v}\right)$ control the diffusion speed for horizontal and vertical directions, respectively. The gravity settling depends on the particle size.

For the computation of convective transport, the wind velocity $V$ is obtained from the global Grid Point Values (GPV) provided by Japan Meteorological Agency (JMA). The gridded data are first interpolated in time onto the model's time steps of every 5 minute. A cubic spline method (see Burden et al., 1981) is used to interpolate the wind data from 6 hour interval to the model's time step. Then, the wind velocity at an arbitrary spatial point is evaluated using the 3-D cubicsplines from the nearby gridded data.

The diffusion of the ash particles is parameterized by the random walk process, where the horizontal diffusion speed $c_{h}$ of the random walk may be related to the horizontal diffusion coefficient $K_{h}$ as follows:

$$
c_{h}=\sqrt{\frac{2 K_{h}}{\Delta t}},
$$

where $\Delta t$ is the time step of the model. The diffusion speed depends on the time increment of the discrete time integration. The same relation holds between the vertical diffusion speed $c_{v}$ and the vertical diffusion coefficient $K_{v}$. We have repeated diffusion tests with various values of diffusion coefficients, and the resulting dispersals are compared with satellite images of actual dispersals for several volcanic eruptions in the past (Yamagata, 1993; Yamamoto, 2000, 2002). With these diffusion tests, we find that the appropriate horizontal diffusion coefficient is $K_{h}=100\left(\mathrm{~m}^{2} \mathrm{~s}^{-1}\right)$. The vertical diffusion is considerably smaller than that of the horizontal diffusion. Since the appropriate value is not known from the satellite observations for the vertical direction, we set $K_{v}=0\left(\mathrm{~m}^{2} \mathrm{~s}^{-1}\right)$ for simplicity in this study. Note that the values may be different for other volcanos and for other weather conditions.

The gravitational settling is based on Stokes Law as a function of the radius of the particle $a_{i}$. The fallout speed $|G|$ is approximated by the terminal velocity below:

$$
|G|=\frac{2 \rho g a_{i}^{2}}{9 \eta}
$$

where $\rho$ is the density of plume particles, $\eta$ the dynamic viscosity coefficient, and $g$ the gravity acceleration. We have assumed a constant of $\rho g / \eta=1.08 \times 10^{9} \mathrm{~m}^{-1} \mathrm{~s}^{-1}$ for simplicity. The actual eruption contains large fragments up to few $\mathrm{cm}$ in radius as well as fine ash over a continuous particle size to less than $1 \mu \mathrm{m}$. Large particles typically settle 


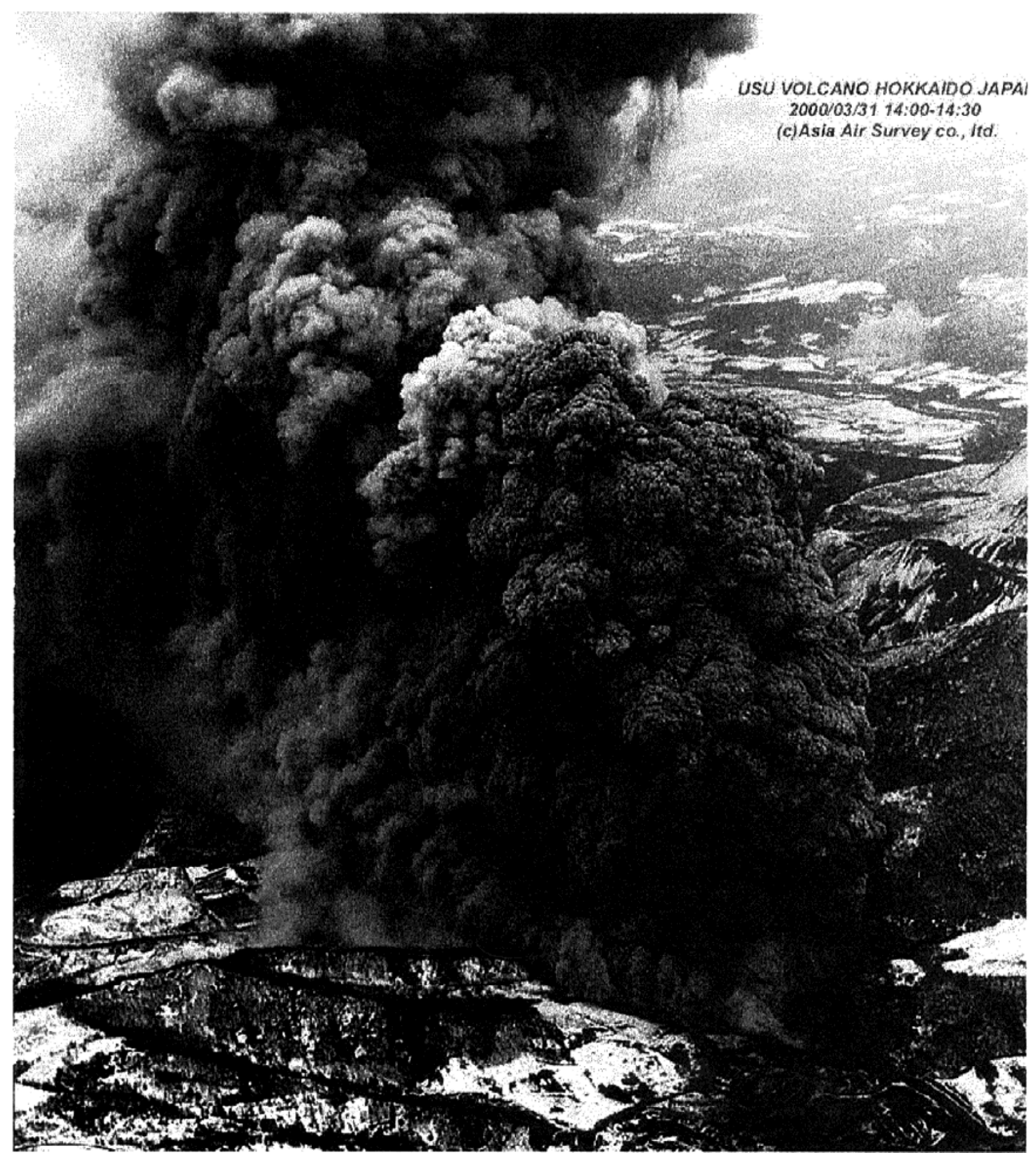

Fig. 1. Eruption of Usu volcano in Hokkaido, Japan on 31 March 2000. Photo is taken from Tohya-mura (Northwest of the vent) between 05:00 and 05:30 UTC (14:00 and 14:30 JST) (by Asia Air Survey Co., Ltd.).

out within a short time, so the particle size spectrum in the air shifts toward the smaller particles. Because we are interested in the particles which can travel for several hours, we have assumed the initial particle size distribution centered at $100 \mu \mathrm{m}$ with an assumption that the size distribution obeys a logarithmic Gaussian distribution with its standard deviation 1.0. Thus, about $95 \%$ of particles are supposed to have their radius between $1 \mu \mathrm{m}$ and $1 \mathrm{~cm}$. Generating Gaussian random numbers, every particle is assigned with its own radius when it appears at the volcanic ash column. In practice, the particles larger than $1 \mathrm{~cm}$ drop quickly within a few steps of the time integrations. The particles less than $100 \mu \mathrm{m}$ can travel far from the source providing important information of the plume dispersion.

Sufficiently large number of particles are contained within the vertical column above the crater of the erupting volcano.
The initial particles are modeled to be uniformly distributed in the vertical column between the top of the volcano and the specified plume top using a uniform random number generator. We have specified the plume top as $3000 \mathrm{~m}$ from the report by Endoh et al. (2001). In a case of a short-time explosive eruption puff, the ash particles are generated only for the initial time of the time integration. When the eruption continues for certain period of time, the model generates new particles over the same vertical column for every time step during the specified eruption period. For a steady eruption, the particle number tends to increase in the model atmosphere before the plume particles have dropped or crossed the vertical wall of the model domain. Therefore, the number of particles released at every time step is adjusted in order to draw optimal statistical information from the model products. For this reason, we set the number of the particles released for a time 
step as 200 in this study. Although it is possible to increase the number toward the limit of the computer capability, the time integration will then be considerably slower, which is a disadvantage for the urgent case. An excessive complication and sophistication are not recommended in the application to the realtime operational prediction.

\section{Results}

Figure 1 shows the erupting volcanic ash from the vent of Usu volcano started at 04:23 UTC (13:23 JST) on 31 March 2000. The photo was taken from Tohya-mura, about $10 \mathrm{~km}$ northwest from the volcano. The first eruption began at 04:07 UTC (13:07 JST). The color of ash cloud was white at the beginning. It then changed to black, shaping like a cauliflower (right-most ash cloud in the figure). The ash cloud moved toward the northeast direction. The plume height reached up to $3000 \mathrm{~m}$ during the first hour. The plume top changed in time ranging from 1000 to $3000 \mathrm{~m}$, depending on the strength of explosion events. It lasted at least till the sunset at 09:00 UTC (18:00 JST), but it may have continued in the dark. The dispersal of the ash clouds was, however, not known once the ash clouds have moved far from the vent. Unfortunately, the satellite observations were not available for this specific event with such a low plume top under the vapor clouds. The airborne ash clouds distant from the vent are still dangerous objects for commercial and non-commercial aircrafts. Yet, no information was available to the public in a realtime basis.

Figure 2 plots the distribution of ash fall for the first eruption event on 31 March observed by University Geological Survey Group and Geological Survey of Japan (see Endoh et al., 2001). The contour represents mass of ash fall over

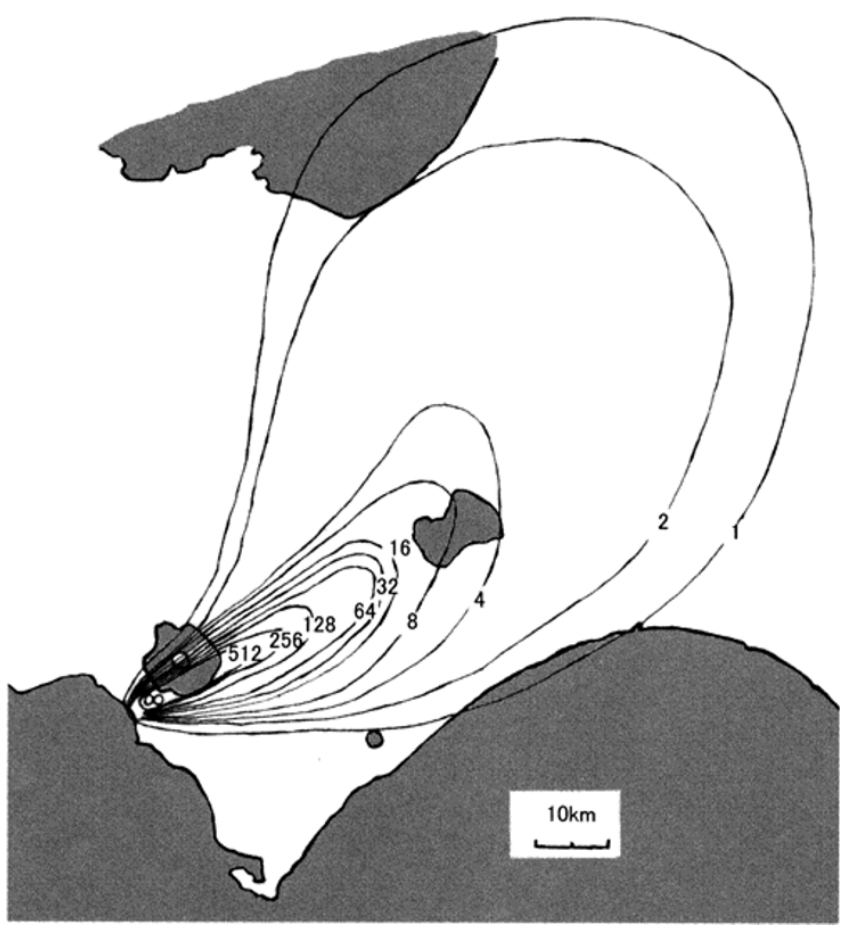

Fig. 2. Distribution of ash fall from Usu volcano for the eruption on 31 March 2000. The units are $10^{-3} \mathrm{~kg} \mathrm{~m}^{-2}$. (After University Geological Survey Group and Geological Survey of Japan.) the unit area $\left(10^{-3} \mathrm{~kg} \mathrm{~m}^{-2}\right)$ with the contour interval of the power of 2. The ash fall was detected on the snow cover on the ground. According to the observation, the axis of the maximum ash fall extends to the northeast around Lake Tohya and to Lake Shikotsu. The ash fall amount is 512 over Lake Tohya which rapidly decreases to 8 over Lake Shikotsu. Then the area bends toward the north of Sapporo city where the amount was measured as 2 . The contour of 1 extends northeast covering the area from Chitose to Otaru city. The falling tephra was reported even at Bibai located $120 \mathrm{~km}$ northeast.

Figure 3 illustrates wind vectors over Hokkaido area at $1000 \mathrm{hPa}$ (white), $850 \mathrm{hPa}$ (gray), and $700 \mathrm{hPa}$ (black) levels at 06:00 UTC (15:00 JST) and 12:00 UTC (21:00 JST), respectively. The grid interval is $1.25^{\circ}$ in longitude and $1.25^{\circ}$

\section{Wind at Usu Volcano 2000033106}

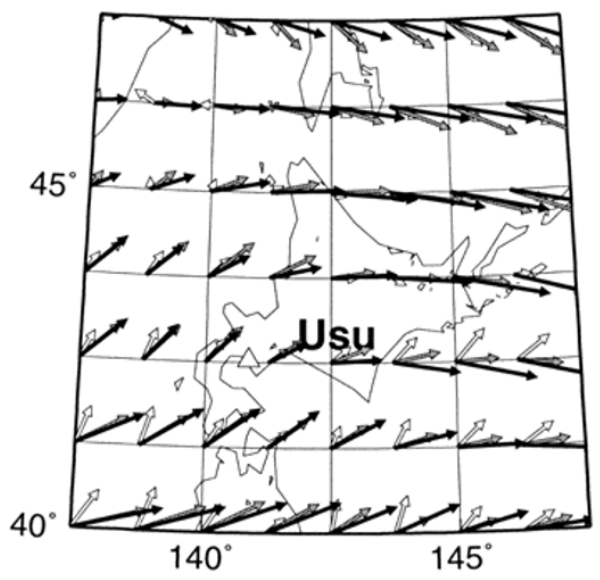

2000033112
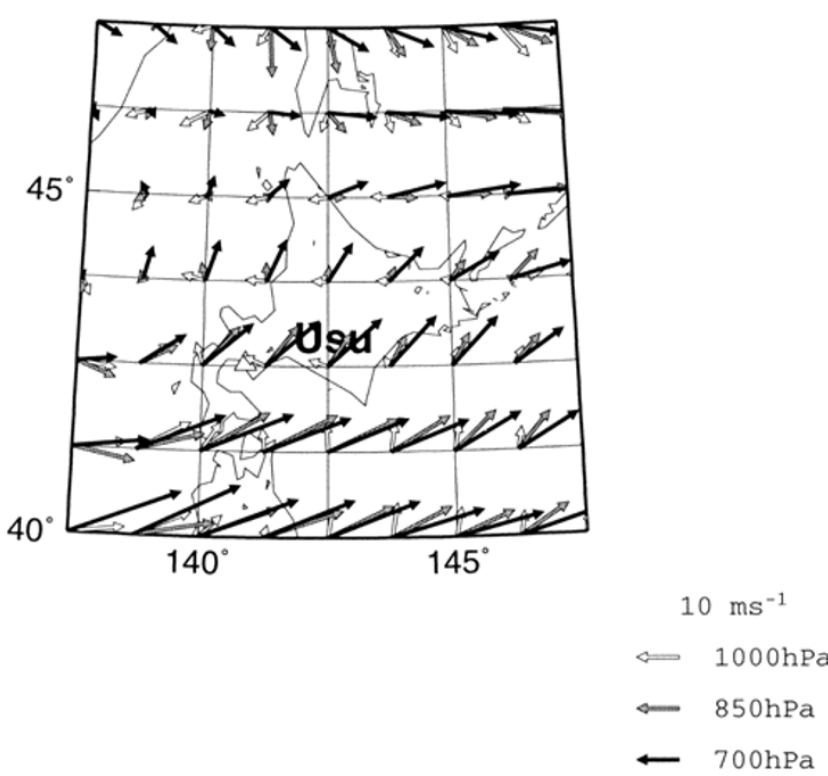

Fig. 3. Wind vectors over Hokkaido area at $1000 \mathrm{hPa}$ (white), $850 \mathrm{hPa}$ (gray), and $700 \mathrm{hPa}$ (black) levels at 06:00 UTC (15:00 JST) and 12:00 UTC (21:00 JST). 
(a) PUFF Simulation for Usu Volcano

Eruption: 4:00 UTC 31 March 2000

Prediction: 5:00 UTC 31 March 2000

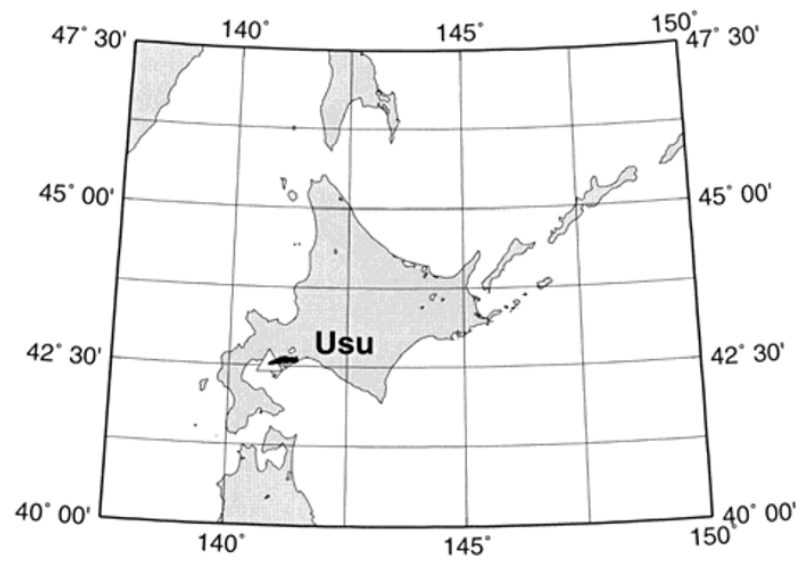

(b)

PUFF Simulation for Usu Volcano

Eruption: 4:00 UTC 31 March 2000

Prediction: 6:00 UTC 31 March 2000

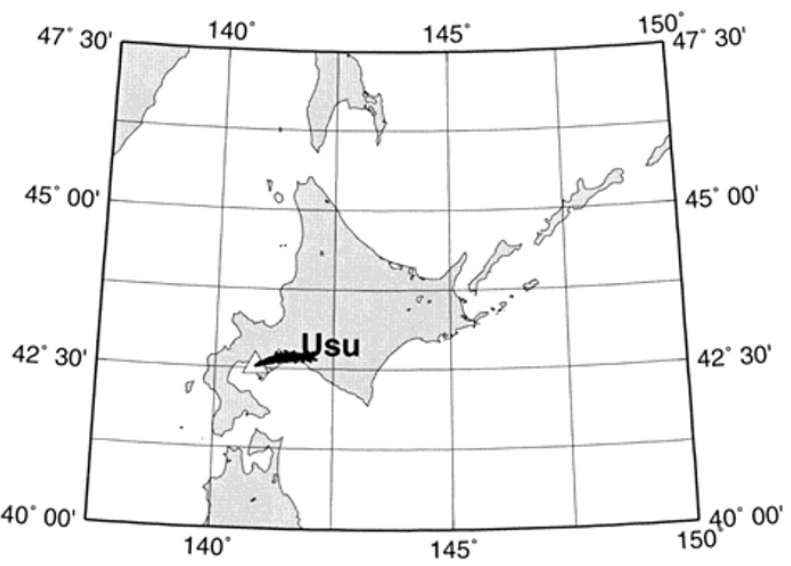

(c)

PUFF Simulation for Usu Volcano

Eruption: 4:00 UTC 31 March 2000

Prediction: 7:00 UTC 31 March 2000

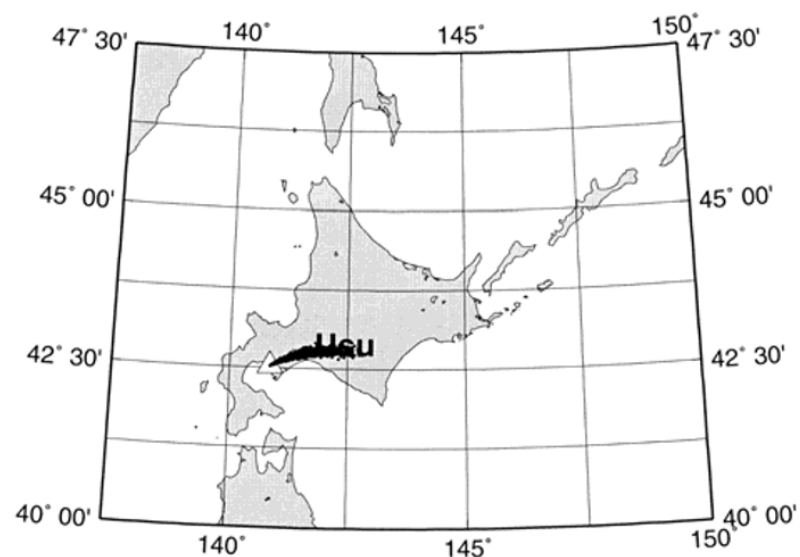

(d)

PUFF Simulation for Usu Volcano

Eruption: 4:00 UTC 31 March 2000

Prediction: 9:00 UTC 31 March 2000

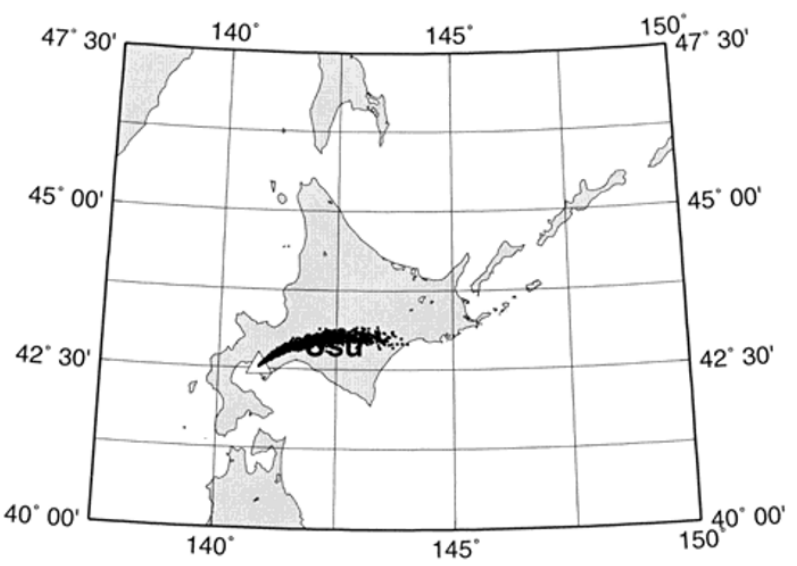

(e) PUFF Simulation for Usu Volcano

Eruption: 4:00 UTC 31 March 2000

Prediction: 11:00 UTC 31 March 2000

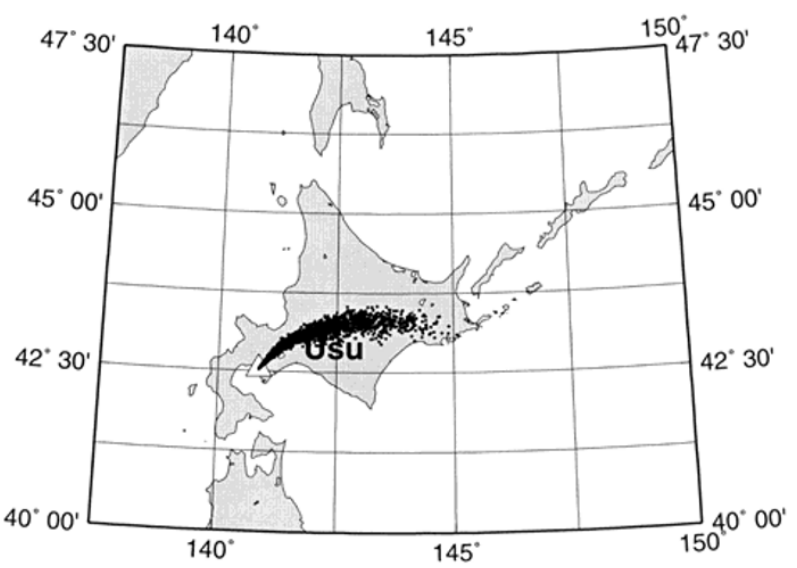

(f) PUFF Simulation for Usu Volcano

Eruption: 4:00 UTC 31 March 2000

Prediction: 13:00 UTC 31 March 2000

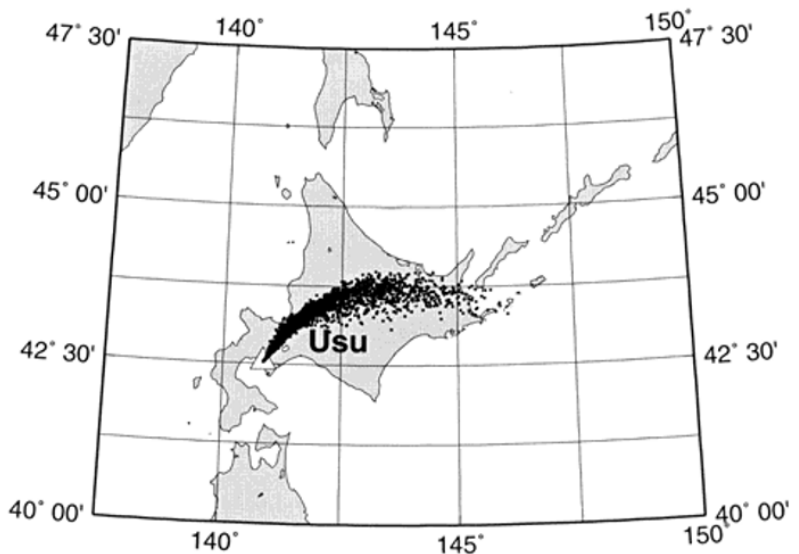

Fig. 4. A model simulation of the volcanic ash plume dispersal from Usu volcano on 31 March 2000 at (a) 05:00 UTC (14:00 JST), (b) 06:00 UTC (15:00 JST), (c) 07:00 UTC (16:00 JST), (d) 09:00 UTC (18:00 JST), (e) 11:00 UTC (20:00 JST), and (f) 13:00 UTC (22:00 JST), respectively. The dots represent particles at all vertical levels projected on the ground. 


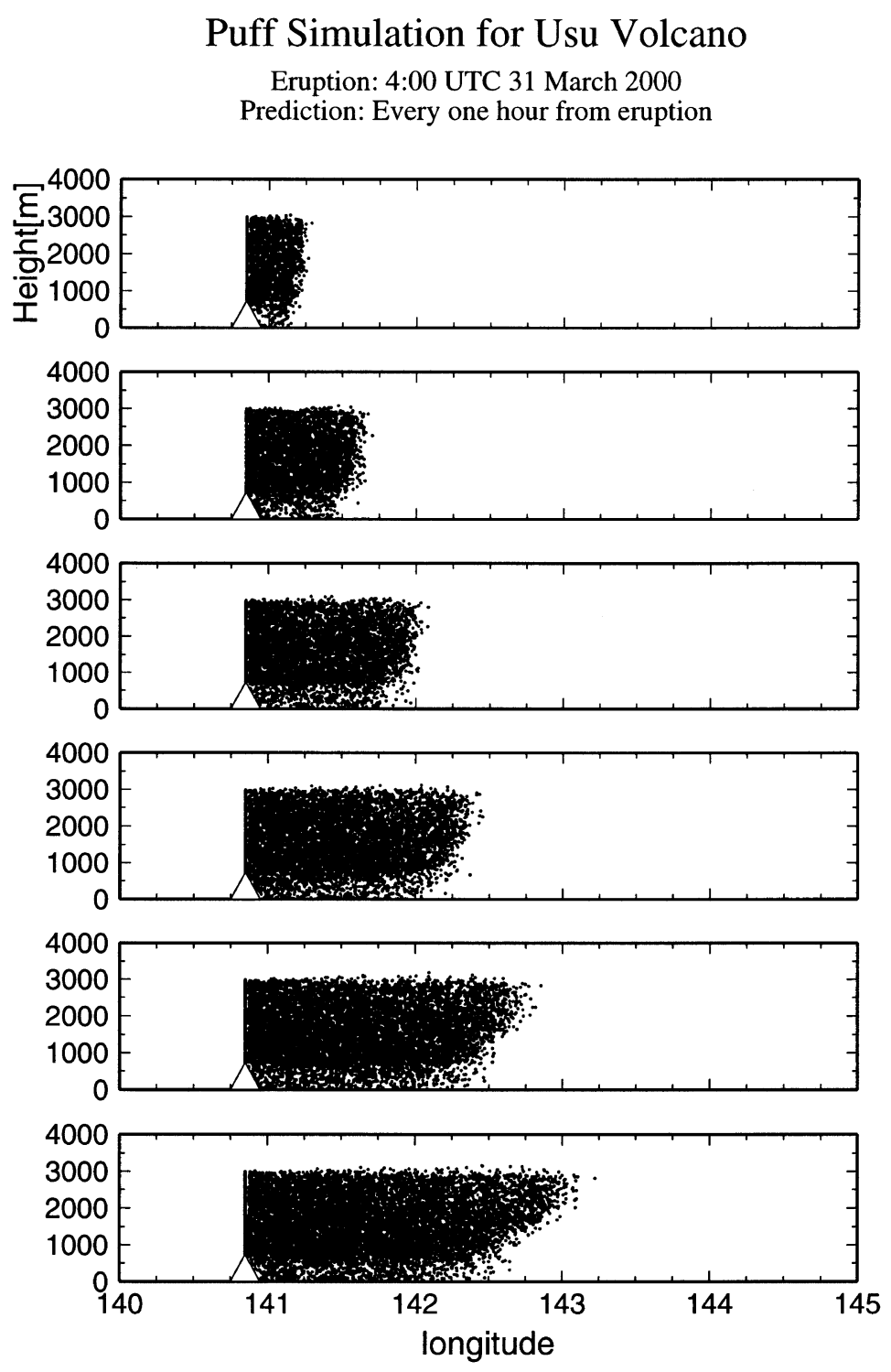

Fig. 5. The vertical-longitudinal section of the simulated hourly ash plume dispersal from Usu volcano on 31 March 2000 from 05:00 to 10:00 UTC (14:00 to 19:00 JST).

in latitude. The wind data are based on the initialized gridded point value (GPV) of the global spectral model (GSM) by the Japan Meteorological Agency (JMA). For the realtime tracking purpose, we need to use a forecasted GPV data which may contain considerable forecasting error compared with the analyzed data. The initialized data are different from the analyzed data, but the horizontal wind may be considered to be close enough to the real observation for the forecasting time range of few hours into the future. The quantitative assessment for the forecasted wind error in GPV/JMA is reported by Fukui (2002). It is discussed that the typical wind error is of the order of $3\left(\mathrm{~m} \mathrm{~s}^{-1}\right)$ in magnitude for the first 24 hours.

According to the distribution of wind vectors at 06:00 UTC (15:00 JST), air flow at $700 \mathrm{hPa}$ curves anticyclonically from the wind direction of southwest over Aomori to west over Nemuro. The direction turns to the northwest over Sakhalin. Over Usu volcano the wind speed is about $10 \mathrm{~m} \mathrm{~s}^{-1}$, and the air flows from southwest to northeast.
Although there is a strong vertical wind shear over the Pacific, the wind shear is almost absent over Usu volcano. The air flow at 12:00 UTC (21:00 JST) curves cyclonically due to the approaching cut-off low over the Sea of Japan. The wind speed over Usu volcano is about $15 \mathrm{~m} \mathrm{~s}^{-1}$ and the direction has shifted about 30 degree southward compared with the previous wind map due to the intensified southerly wind. Over $850 \mathrm{hPa}$ level, the wind direction turns to be more southward over Usu volcano showing a minor wind shear. The direction at $1000 \mathrm{hPa}$ level is southeast although the wind speed is relatively small.

Figure 4 illustrates the horizontal distributions of volcanic ash plume dispersal from Usu volcano on 31 March 2000 from 05:00 UTC (14:00 JST) to 13:00 UTC (22:00 JST) predicted by the PUFF model. The figure describes the 2-D projection of all particles in the air onto the ground. In the model simulation the eruption is assumed to begin at 04:00 UTC (13:00 JST). At 05:00 UTC (14:00 JST), one hour after the eruption, the plume moves just eastward 


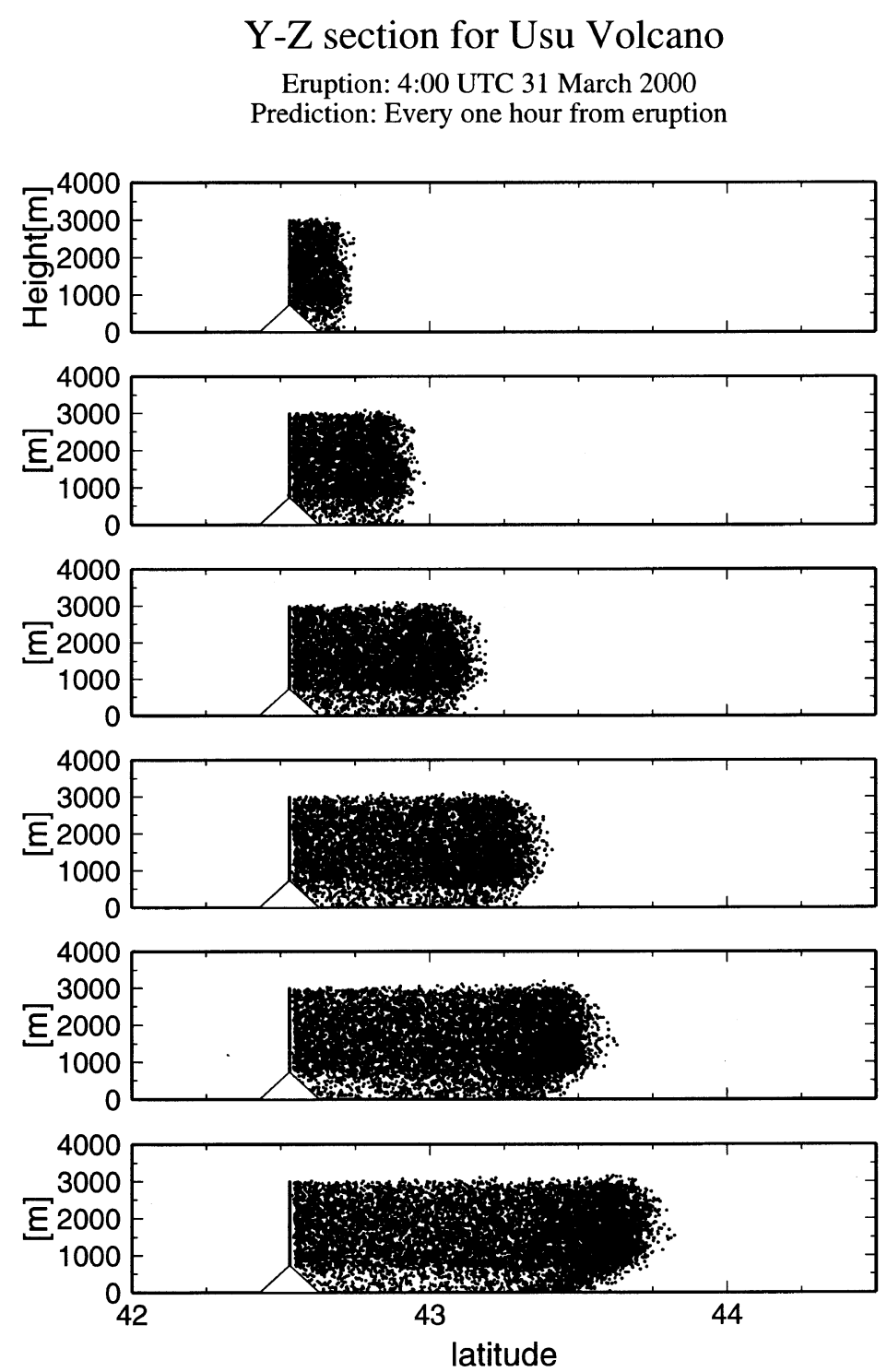

Fig. 6. The vertical-latitudinal section of the simulated hourly ash plume dispersal from Usu volcano on 31 March 2000 from 05:00 to 10:00 UTC (14:00 to 19:00 JST).

about $50 \mathrm{~km}$ from the vent. At 06:00 UTC (15:00 JST), two hours after the eruption, the plume front moves around the northern edge of the Chitose International Airport. AT 07:00 UTC (16:00 JST), three hours after the eruption, the plume front moves $200 \mathrm{~km}$ from the vent reaching Hidaka mountains. AT 09:00 UTC (18:00 JST), five hours after the eruption, the plume travels over Tokachi plain, and the front is about to reach Pacific Ocean. AT 11:00 UTC (20:00 JST), seven hours after the eruption, the plume front shifted northward over Kushiro. We notice intensified southerly wind by that time, so that the continuous release of the ash plume bends toward northward. Therefore, the route of the plume has shifted from the Chitose International Airport area to Sapporo city area. AT 13:00 UTC (22:00 JST), nine hours after the eruption, the plume route extends over Sapporo city to Asahikawa city, and the front has reached Kunashiri Island bending northward. The mean speed of the plume front is estimated as $50 \mathrm{~km}$ per hour, which corresponds to $14 \mathrm{~m} \mathrm{~s}^{-1}$. The speed is consistent with the wind vectors in Fig. 3.

Figure 5 illustrates the vertical cross sections along a longitudinal line at the latitude of Usu volcano located at $140.85^{\circ} \mathrm{E}$ marked by white triangles. The figures are plotted for every one hour during the first six hours from the eruption. The ash plume is released from the volcanic vent continuously with its top height set at $3000 \mathrm{~m}$. According to the cross sections, the ash clouds moved eastward with the speed of $14.2 \mathrm{~m} \mathrm{~s}^{-1}$ at the top level. The speed is reduced to about a half at the ground level, creating a wedge-like shape. Large part of the particles precipitate from higher levels and ultimately fall out to the ground level.

The same vertical cross sections along a latitudinal line are plotted in Fig. 6. It is noticed that the plume is transported northward with the speed of $3.7 \mathrm{~m} \mathrm{~s}^{-1}$. Compared with the cross section along the longitudinal line in Fig. 5, the speed is almost identical for all vertical levels in Fig. 6. The dense ash cloud near the ash front is due to the bending shape as seen in Fig. 4.

The 3-D perspective image of the volcanic plume is illustrated in Fig. 7 for 13:00 UTC (22:00 JST). Each particle has a shape of spherical symbols and the particles lower than 


\section{Puff Simulation for Usu Volcano \\ Eruption: 4:00 UTC 31 March 2000 \\ Prediction: +09 hours}

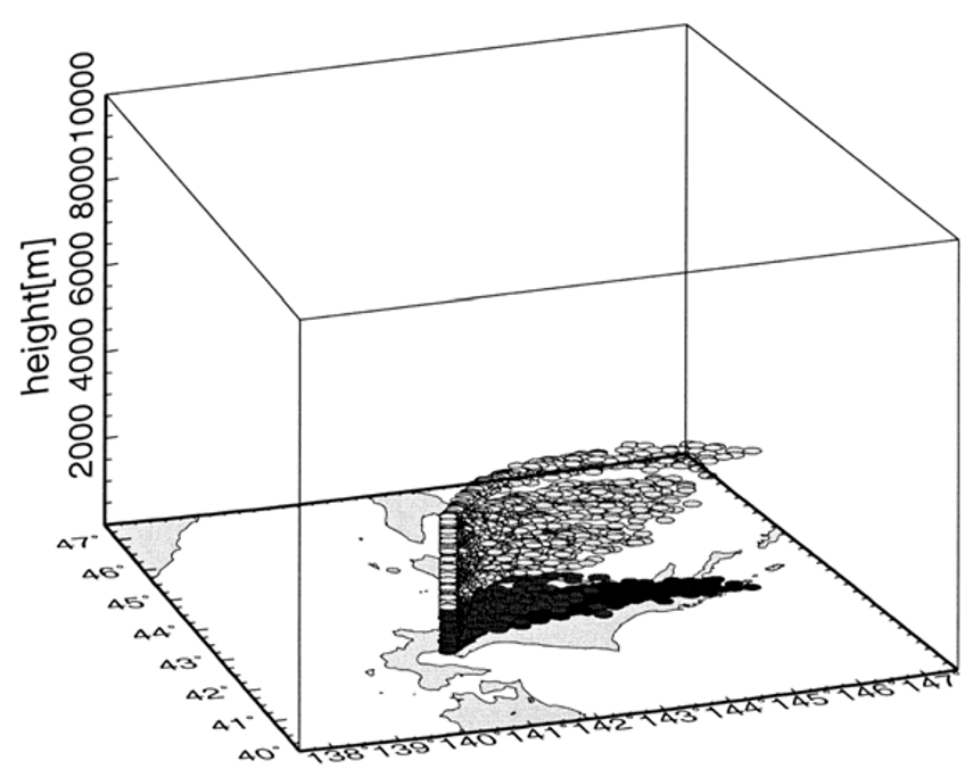

Fig. 7. The 3-D perspective image of the volcanic ash plume dispersal from Usu volcano on 31 March 2000 at 13:00 UTC (22:00 JST). The white, grey, and black symbols represent particles higher than $1000 \mathrm{~m}$, lower than $1000 \mathrm{~m}$, and the projection onto the ground.

Fall map of PUFF Simulation for Usu Volcano

200003310400 UTC eruption

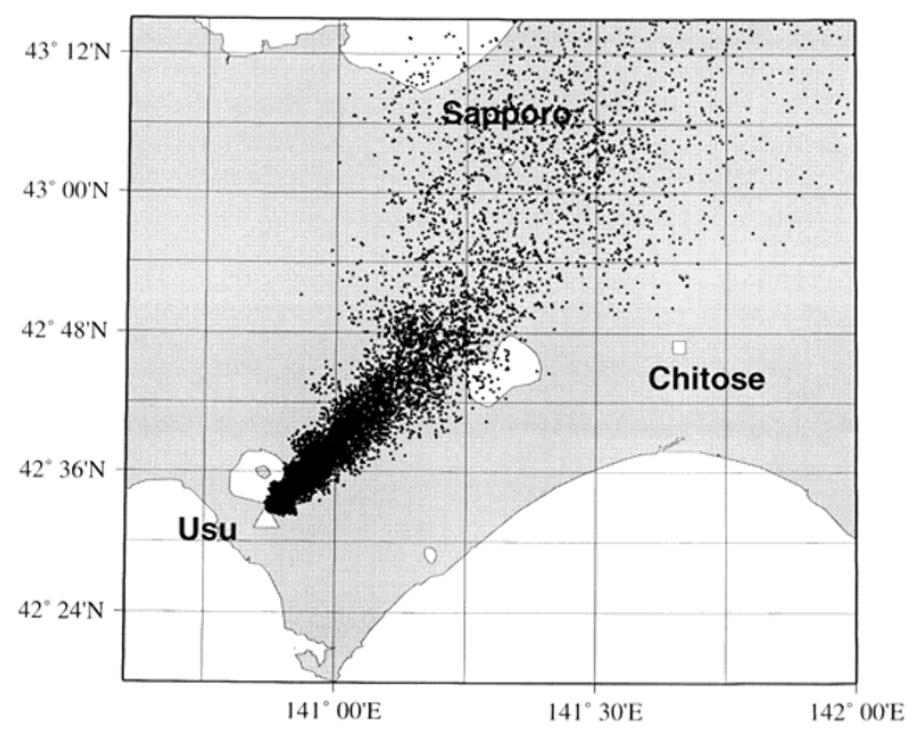

Fig. 8. Distribution of simulated ash fall from Usu volcano for the eruption on 31 March 2000. The black dots represent the location of particles falling on the ground.

$1000 \mathrm{~m}$ are designated by dark symbols. Each particle is projected onto the ground level as plotted by black dots. According to this snapshot, a column of ash particles are first released above Usu volcano then transported northeastward to Sapporo city. The particles are transported eastward bending toward Kunashiri Island. The distributions presented by the horizontal plain (Fig. 4), and vertical cross sections along the longitudinal (Fig. 5) and latitudinal (Fig. 6) lines are con- 
cisely represented by this 3-D perspective image. It may be important to note that the snapshot shape is different from the trajectory of particles since the flow is not steady. The former bends clockwise whereas the latter bends anti-clockwise.

Figure 8 plots the distribution of ash fall from Usu volcano simulated for the eruption on 31 March 2000. The black dots represent the location of particles falling onto the ground level. For simplicity, the surface topography is not considered, and every fallout is expressed by the same size of black dot. Nevertheless, a dense and concentrated fallout is seen near the volcanic vent extending northeastward to the northern edge of Lake Shikotsu. The fallout is ranging from northern edge of the Chitose International Airport to Otaru city. It is evident that Sapporo city is just a northern flank of the fallout zone.

By counting the total mass of ash fall over a unit area, we can draw contours of ash fall amount. Figure 9 illustrates the mass distribution evaluated from the result in Fig. 8, assuming a proper ash density normalized and adjusted by the total amount of ash released. The contours are in logarithmic scale with a base ten. The axis of the maximum fallout extends from the vent to Lake Shikotsu bending toward the north of Sapporo area. The result of Fig. 9 may be compared well with the observed distribution of the ash fall in Fig. 2. Although the simulated distribution indicates a slight northward shift, the agreement between the simulated and observed fallout distributions may be quite reasonable. Based on this agreement, we can justify that the movement of volcanic ash plume in the air simulated by the PUFF model is reasonable. The observed ash fallout seems to spread much wider than the PUFF model simulation partly due to the boundary layer turbulent mixing due to the surface topography which is not considered by the PUFF model. The inclusion of topography and the boundary layer process may improve the fallout distribution. Such an improvement may be reserved for the future works.

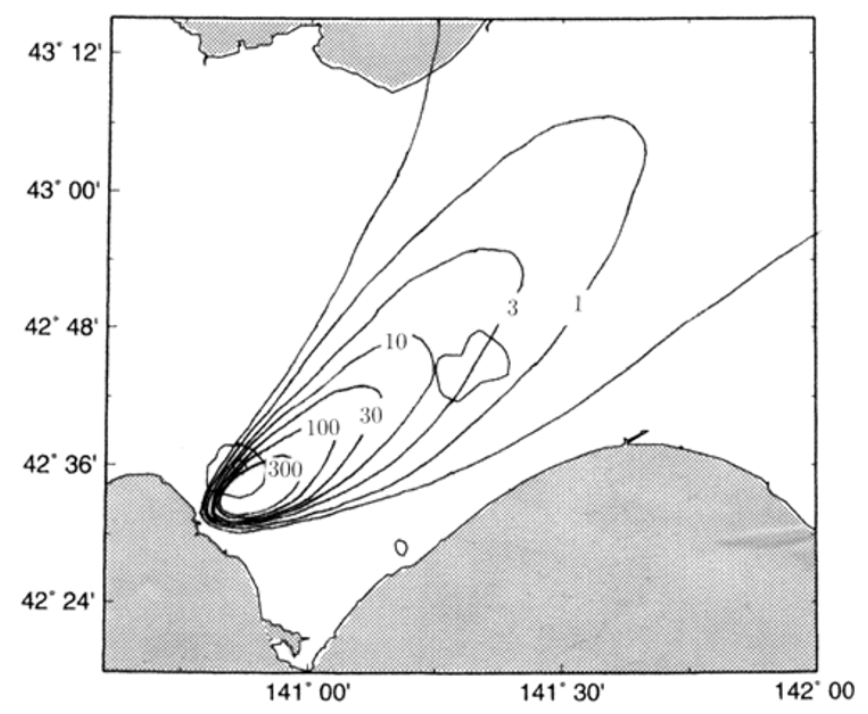

Fig. 9. Normalized ash fall distribution evaluated by the distribution in Fig. 8. The contours are in logarithmic scale with a base ten, so the value is proportional to the mass distribution as in Fig. 2.

\section{Concluding Summary}

Volcanic ash cloud floating and traveling in the air is a dangerous object for commercial and non-commercial aircrafts. In order to avoid encounters with ash cloud, a realtime volcanic plume prediction model, called PUFF, has been developed by Tanaka (1994) and Searcy et al. (1998) for Alaska volcanos. The performance of the volcanic ash tracking model must be checked whenever it is possible by applications to actual eruptions occurring in the world. The eruption of Usu volcano on 31 March 2000 in Hokkaido has provided us a valuable opportunity to demonstrate the model performance because Usu volcano is surrounded by dense and advanced monitoring systems.

In this study, the PUFF model was applied to the actual eruption of Usu volcano to infer the movement of the ash clouds in the air. The result of the PUFF model simulation starting at 04:00 UTC (13:00 JST) is summarized as follows:

(1) Ash plume erupted from Usu volcano first moved toward east for the New Chitose International Airport. The ash front reached the northern flank of the International Airport at about 05:30 UTC (14:30 JST), 90 min after the eruption.

(2) The upper air westerly wind gradually shifted to southerly wind about five to ten hours after the eruption. While the ash front traveled over Nemuro about ten hours after the first eruption, the subsequent plumes from Usu volcano moved toward northeast over Sapporo city.

(3) The dense ash fall first extended from Lake Shikotsu to the northern edge of the New Chitose International Airport. The ash fall gradually extended to the north of Sapporo city especially by the low-level wind while the upper air wind kept moving toward Lake Shikotsu.

The result of the numerical simulation was compared with the ground truth of the observed distribution of tephra on the ground. It may be important to note that such a movement of volcanic ash clouds in the air was not available in a real time basis. The 24-hour TV monitoring showed the erupting volcano and rising ash plume. Yet, the dispersal of the ash clouds was not known once the ash clouds have moved far from the vent. The airborne ash clouds distant from the vent are still dangerous objects for commercial and non-commercial aircrafts. The exact location and dispersal of the ash plume traveling in the air may be detectable from the satellite (Sawada, 1989). However, in this event, the ash plume is easily obscured by ordinary meteorological vapor clouds. The sophisticated monitoring system such as satellite observation was sometimes not useful for relatively lower ash cloud in the troposphere under the dense meteorological clouds. The dangerous ash clouds are in most case indistinguishable from the ordinary vapor clouds by the satellite observation although the distribution of black tephra on white snow is clearly detachable. For this reason, the numerical model prediction with accurate wind information becomes a powerful tool to speculate the location of the airborne ash in real time and to release the warning to the public as well as the aviation industry. 
Acknowledgments. The authors are grateful to the support rendered by Drs. S. Akasofu, K. Dean, J. Dehn, J. Tilley, and K. Papp of the University of Alaska. Thanks are extended to Dr. C. Searcy of NWS/NOAA, Mr. S. Onodera of JAL, Mr. S. Shimoda and Ms. S. Yamagata of JWA, for their useful comments. The authors appreciate Ms. K. Honda, Mr. M. Masamitsu, and Mr. D. Nohara for their technical assistance. This research was supported by the IARC/NASDA research project: Modeling the dynamics of volcanic eruption cloud.

\section{References}

Akasofu, S.-I. and H. L. Tanaka, Urgent issue of developing volcanic ash tracking model, Kagaku Asahi, 5, 121-124, 1993 (in Japanese).

Armienti, P. and G. Macedonio, A numerical model for simulation of tephra transport and deposition: Application to May 18, 1980, Mount St. Helens eruption, J. Geophys. Res., 93, 6463-6476, 1988.

Burden, R. L., J. D. Faires, and A. C. Reynolds, Numerical Analysis, 598 pp., Prindle, Weber and Schmidt, 1981

Casadevall, T. L., The 1989-1990 eruption of Redoubt volcano, Alaska: Impacts on aircraft operations, J. Volcanol. Geotherm. Res., 62, 301-316, 1994.

Chatfield, C., The Analysis of Time Series: An Introduction, 286 pp., Chapman and Hall, 1975.

Dean, K. G., S. I. Akasofu, and H. L. Tanaka, Volcanic hazards and aviation safety: Developing techniques in Alaska, FAA Aviation Safety Journal, 3(1), 11-15, 1993.

Endoh, K., M. Ohno, M. Kunikita, M. Morohoshi, M. Suzuki, Y. Nishimura, D. Nagai, T. Chiba, and I. Tohno, Pheatomagmatic explosions of the 2000 eruption of Usu volcano, Natural Science Reports, Nihon University, 36, 65-73, 2001 (in Japanese).

Fukui, T., Assessment of wind error in GPV/JMA prediction model used for the volcanic plume tracking model PUFF, Graduation Thesis, Natura Science, University of Tsukuba, 70 pp., 2002.

Glaze, L. S. and S. Self, Ashfall dispersal for the 16 September 1986 , eruption of Lascar, Chile, calculated by a turbulent diffusion model, Geophys. Res. Let., 18, 1237-1240, 1991

Heffter, J. L. and B. J. B. Stunder, Volcanic ash forecast transport and dispersion (VAFTAD) model, Computer Techniques, 8, 533-541, 1993.

Hobbs, P. V., L. F. Radke, J. H. Lyons, R. J. Ferek, D. J. Coffman, and T. J. Casadevall, Airborne measurements of particle and gas emissions from the 1990 volcanic eruption of Mount Redoubt, J. Geophys. Res., 96 , 18735-18752, 1991.

Hurst, A. W. and R. Turner, Performance of the program ASHFALL for forecasting ashfall during the 1995 and 1996 eruptions of Ruapehu volcano, New Zealand, J. Geol. Geophys., 42, 615-622, 1999.

Kai, K., Y. Okada, O. Uchino, I. Tabata, H. Nakamura, T. Takasugi, and
Y. Nikaidou, Lidar observation and numerical simulation of Kosa (Asian Dust) over Tsukuba, Japan, during the spring of 1986, J. Meteor. Soc. Japan, 66, 457-472, 1988.

Kienle, J., A. W. Woods, S. A. Estes, K. Ahlnaes, K. G. Dean, and H. L. Tanaka, Satellite and slow-scan television observations of the rise and dispersion of ash-rich eruption clouds from Redoubt volcano, Alaska, EOS, 72(2), 748-750, 1991

Onodera, S., Volcanic activity and flight operations, Aviation Meteorological Notes, 45, 13-30, 1997.

Praham, L. P. and O. Christensen, Long-range transmission of pollutant simulated by a two-dimensional pseudo spectral dispersion model, $J$. Appl. Meteor., 16, 896-910, 1977.

Sawada, Y., The detection capability of explosive eruptions using GMS imagery, and the behavior of dispersing eruption clouds, IVAVCEI, in Proceedings in Volcanology 1, edited by J. H. Latter, pp. 233-245, Volcanic Hazards, Springer-Erlag Berlin Heidelberg, 1989.

Searcy, C., K. Dean, and B. Stringer, PUFF: A volcanic ash tracking and prediction model, J. Volc. Geophys. Res., 80, 1-16, 1998.

Suck, S. H., E. C. Upchurch, and J. R. Brock, Dust transport in Maricopa county, Arizona, Atmos. Environ., 12, 2265-2271, 1978.

Tanaka, H. L., Development of a prediction scheme for the volcanic ash fall from Redoubt volcano, First Int'l. Symp. on Volcanic Ash and Aviation Safety, Seattle, Washington, U.S. Geological Survey Circular 1065:58, 1991

Tanaka, H. L., Development of a prediction scheme for volcanic ash fall from Redoubt volcano, Alaska, Proc. First International Symposium on Volcanic Ash and Aviation Safety, U.S. Geological Survey, Bulletin 2047, 283-291, 1994.

Tanaka, H. L., K. G. Dean, and S. I. Akasofu, Predicting the movement of volcanic ash clouds, EOS, 74(20), 231-231, 1993.

Tokyo Aviation Weather Service Center, Volcanic ash advisory service, Japan Meteorological Agency, Geophys. Maga. Ser. 2, 4, 1-4, 2001.

Turner, R. and T. Hurst, Factors influencing volcanic ash dispersal from the 1995 and 1996 eruptions of Mount Ruapehu, New Zealand, J. Appl. Meteor., 40, 56-69, 2001.

Yamagata, S., Development of volcanic plume prediction scheme for aviation safety, Graduation Thesis, Natural Science, University of Tsukuba, 136 pp., 1993.

Yamamoto. K., Numerical experiment of the volcanic ash cloud dispersion and the justification by satellite image, Graduation Thesis, Natural Science, University of Tsukuba, 87 pp., 2000.

Yamamoto, K., Numerical experiments and the assessment for the probability of the volcanic ash dispersal, Master thesis, Graduate School of Life and Environmental Sciences, University of Tsukuba, 70 pp., 2002.

H. L. Tanaka (e-mail: tanaka@atm.geo.tsukuba.ac.jp) and K. Yamamoto 